\title{
Long Term Use of Antipsychotics and Adverse Effects on Bone Density
}

\author{
Ahmed Rady1,†,Adel Elsheshai1,Osama Elkholy1, Heba Abouelwafa1, Mohamed Eltawil2
}

\begin{abstract}
Background and Objectives

High incidence of osteoporosis and pathological fractures were observed in schizophrenic patients medicated by antipsychotics for long time. Hyperprolactinemia induced by antipsychotics may partially contribute to osteopenia. Though atypical antipsychotics cause less hyperprolactinemia than conventional antipsychotics, however, risperidone and amisulpride seem to have no advantage in this regard. Our study aims at assessing effect of long term use of antipsychotics on bone density.
\end{abstract}

\section{Methods}

30 schizophrenic patients on antipsychotics for 2-10 yrs were recruited compared to control drug naiff schizophrenic group for bone mineral density Results: both groups were balanced for age and gender distribution. Significantly decreased bone mineral density was found among schizophrenic patients on long term use of antipsychotics $\left(X^{2}=3.25 ; p<0.05\right)$. This later had significantly higher serum prolactin $(p<0.001)$ and lesser serum cortisol level $(p<0.01)$.

\section{Conclusion}

Osteopenia and osteoporosis are common adverse effects among antipsychotics, though can easily be screened for, but it's often a forgotten side effect with impact on general health state.

\section{Keywords}

Schizophrenia, Antipsychotic,Osteopenia, Bone Density, Cortisol, Hyperprolactinemia

\section{Introduction}

Osteoporosis is characterized by abnormally low bone mineral density leading to impaired bone tissue structure and a rising risk for pathological fractures. WHO defines osteoporosis as a spinal or hip bone mineral density BMD of 2.5 standard deviations or more below the mean for healthy individual as measured by dual energy $\mathrm{X}$ ray Absorptiometry DEXA. Diverse secondary causes of osteoporosis as thyrotoxicosis, hyperparathyroidism, malignancies, renal failure are under focus in relevant scientific literature
[1-3]. An indirect causality relation between the use of antipsychotics and increased prevalence of osteoporosis have been reported in literature $[4,5]$.

One hypothesis is linked to the fact that long term use of antipsychotics are the commonest pharmacologic etiology for chronic hyperprolactinemia which consecutively leads to decreased serum level of sex hormones and decreased mineralization of bones [6]. Though hyperprolactinemia is a common side effect of conventional antipsychotics, it's much less

'Department of Psychiatry, Alexandria University School of Medicine

2El Mamoura Psychiatric Hospital, Alexandria, Egypt

${ }^{\dagger}$ Author for correspondence: Ahmed Rady, 29, Nabi Daniel St. Alexandria 21131 -Egypt, Tel: +2 01282441053; email: dr_ahmed_rady@ yahoo.fr 
reported with atypical antipsychotics. However, risperidone and amisulpride are not better than conventional antipsychotics in this issue [7].

Different hypothesis have been suggested by authors explaining increased osteoporosis and pathological fractures among schizophrenic patients on antipsychotic medications

Genetic susceptibility: patients with schizophrenia have shorter life span, osteopenia and worse general health state compared to normal population, genetic framework can partially explain increased morbidity and mortality among this category of patients. Low bone density has been found to be genetically predetermined in more than $70 \%$ of cases, and presence of a osteoporosis-related hip fracture in mother can double the risk in their postmenopausal daughters. Such common genetic susceptibility that confers a higher bone microarchitecture morbidity and psychopathology is still an area of research with much more to be elucidated in future [8].

Hyperprolactinemia induced hypogonadism: conventional antipsychotics as well as some atypical ones particularly risperidone and amisulpride are the commonest cause of drug induced prolactinemia, studies in mice models show that long term use of antipsychotics can lead to hypogonadism and poor trabecular bone density, such findings have been replicated in ovariectomized mice where ovaries have been removed indicating that hypogonadism alone cannot explain antipsychotic-induced osteoporosis. Studies show osteoporosis was even more in ovariectomized mice receiving antipsychotics [9].

Central CNS mechanism: Antipsychotics do have variable and diverse complex antagonism on various G-protein coupled receptors including dopaminergic, adrenergic, cholinergic and histaminergic receptors. Sertonergic and dopaminergic signaling have been implicated directly in central regulatory mechanism for bone biology. Bone turnover is found to be correlated with sympathetic system output to bones. Antipsychotics can regulate such sympathetic output. Leptin hormone dysregulation has been found not only to be related to increased body weight with antipsychotics but also play a major role in regulating sympathetic discharge to bones [10]. Studies found that co-administration of beta blockers with antipsychotics decreases druginduced osteoporosis [11].
Direct accumulation in bone marrow: studies in mice show that antipsychotics' level in bone marrow can exceed 10 times it's level in blood, one to three hours after administration. And it can still be found in bone marrow far longer after disapprearance from blood when medication is stopped, indicating a tendency for antipsychotics to accumulate in bone marrow for long periods. Taking in consideration strong presence of serotonin and dopamine receptors on both osteoclasts and osteoblasts, render a 'direct bone effect' hypothesis a possible etiology of drug induced steoporosis $[12,13]$.

Our study aims at assessing bone mineral density among chronic schizophrenic patients with long term use of antipsychotics.

\section{Materials and Methods}

The design is a comparative cross sectional study approved by the ethics committee of Alexandria University school of medicine. All participants gave written consent and purpose of the study well explained.

50 patients were recruited from Alexandria University Hospital out patient service, 30 chronic schizophrenic patients with duration between 2 and 10 years according to records with long term use of antipsychotics, and 20 schizophrenic patients drug naï as control group. Diagnosis was made by a structural clinical interview based on DSM 5 criteria [14]. Both genders aged between 20-40 yrs were included. Patients with chronic debilitating medical illness, mentally retarded, hyo or hypercalcemia, on steroid therapy or having history of thyroid dysfunction or relevant endocrinological diseases were excluded. These studies assess osteoporosis among schizophrenic patients on antipsychotic medication in Egyptian population where relevant information to this issue is lacking for such ethnic group.

All participants had level of prolactin and chortisol assessed between 8:00 and 9:00 am. Prolactin was evaluated by IMx prolactin assay, a microparticle enzyme immunoassay MEIA for quantitative measurement of prolactin in serum [15]. Cortisol level was measured by radioimmunoassay and serum concentration of DHEAS was measured by chemiluminescent enzyme immunoassay [16].

Bone miniral density was measured by Dual energy X- ray Absorptiometry DEXA, ensity is assessed by a $\mathrm{T}$-score for bone mineral density. 
Normally it should be $\geq-1$ SD. In osteopenia it falls between -1 and -2.5 SD while osteoporosis falls $\leq-2.5$ SD. SD here stand for standard deviation for mean density in healthy individuals [17].

\section{- Statistical analysis}

After data collection, they were fed into computer after coding using Statistical Package for Social sciences SPSS version 11.5 for data analysis and tabulation. Descriptive analysis were done, parametric values arithmetic mean, median and standard deviations were calculated, Student $t$ test was used as parametric testing measurement and Chi square test was used as non-parametric testing tool. Type one statistical error was set $<0.05$

\section{Results}

\section{- Descriptive statistics}

Both groups were balanced in terms of age and gender distribution Table 1.

Among schizophrenic patients, $12(40 \%)$ and $18(60 \%)$ were receiving Haloperidol and risperidone respectively, with an average duration of treatment $5.27 \pm 2$ yrs.

\section{- Inferential statistics}

Schizophrenic patients with long term use of antipsychotics showed significantly decreased bone mineralization, higher prevalence of osteoporosis, higher levels of prolactin and lesser levels of cortisol with a statistically significant difference as shown in Table 2.
Same parameters among male and female subcategories didn't show a gender sensitive difference Table 3 and Table 4.

\section{Discussion}

Our study, all chronic schizophrenic patients with long term use of antipsychotics showed poor bone mineral density with prevalence of $70 \%$ osteopenia and 30\% osteoporosis which highlights the importance of an often overlooked adverse effect.

Our results of high prevalence of poor bone mineralization comes in agreement with many predecessor authors, though varying prevalence rates may be attributed to difference in patients selection criteria for age, ethnic background and instruments used for quantitatively assess bone mineral density [18-20]. Our study had recruited young patients with mean age of $30.73 \pm 6.19$ and $30.5 \pm 6.75$ for schizophrenic patients on antipsychotics and drug naif respectively, and all patients above 40 were not recruited. Such high prevalence rate of osteopenia and consecutively higher risk for pathological fractures is a public health alarm, taking in consideration frequent falls with antipsychotics particularly risperidone due to postural hypotension [21].

Our results confirm previous findings that showed decreased cortisol level with long term use of antipsychotic, and authors explained such findings by better control of pseudo stressful conditions related to psychotic symptoms as perceptual abnormalities like hallucinatory phenomena and persecutory delusions that

\begin{tabular}{|c|c|c|c|}
\hline & $\begin{array}{l}\text { Schizophrenic patients with long term use of antipsychotics } \\
\text { (Group 1) N=30 }\end{array}$ & $\begin{array}{l}\text { Drug naif schizophrenic patients (Group 2) } \\
\mathrm{N}=\mathbf{2 0}\end{array}$ & Statistical test \\
\hline Age & $30.73 \pm 6.19$ & $30.5 \pm 6.75$ & $t=0.98$ \\
\hline $\begin{array}{l}\text { Gender } \\
\text { Male } \\
\text { Female }\end{array}$ & $\begin{array}{l}\text { No. } \\
19 \\
11\end{array}$ & $\begin{array}{l}\text { No. } \\
11 \\
9\end{array}$ & $X^{2}=0.68$ \\
\hline${ }^{*} p<0.05$ & & & \\
\hline
\end{tabular}

\begin{tabular}{|l|l|l|l|}
\hline Table 2: Comparison between both groups as regards Bone density, cortisol and prolactin levels. \\
\hline & $\begin{array}{l}\text { Schizophrenic patients with long term use of antipsychotics } \\
\text { (Group 1) N=30 }\end{array}$ & $\begin{array}{l}\text { Drug naïf schizophrenic patients (Group 2) } \\
\mathbf{N}=\mathbf{2 0}\end{array}$ & Statistical test \\
\hline Prolactin & $81.3 \pm 4.99$ & $22.5 \pm 2.45$ & $\mathrm{t}=49.25^{*}$ \\
\hline Cortisol & $16.15 \pm 5$ & $24.1 \pm 7.1$ & $\mathrm{t}=4.98^{*}$ \\
\hline $\begin{array}{l}\text { Bone Density } \\
\text { BMD -T-score }\end{array}$ & No. & No. & \\
\hline$\geq-1$ SD & 0 & 5 & $\mathrm{X}^{2}=3.25^{*}$ \\
\hline$-1,-2.5$ SD & 21 & 14 & \\
$\leq-2.5$ SD & 9 & 1 & \\
\hline${ }^{*} \mathbf{p}<\mathbf{0 . 0 5}$ & & & \\
\hline
\end{tabular}


Research Ahmed Rady

\begin{tabular}{|c|c|c|}
\hline $\begin{array}{l}\text { Bone Mineral Density BMD } \\
\text { (T-score) }\end{array}$ & $\begin{array}{l}\text { Schizophrenic patients with long term use of } \\
\text { antipsychotics }(N=30)\end{array}$ & Drug naïf schizophrenic patients ( $N=20$ ) \\
\hline $\begin{array}{l}\text { AP spine (L1-L4) } \\
\geq-1 \mathrm{SD} \\
-1 \text { to }-2.5 \mathrm{SD} \\
\leq-2.5 \mathrm{SD}\end{array}$ & $\begin{array}{l}0 \\
21 \\
9\end{array}$ & $\begin{array}{l}5 \\
14 \\
1\end{array}$ \\
\hline $\begin{array}{l}\text { Left Femur } \\
\geq-1 \text { SD } \\
-1 \text { to }-2.5 S D \\
\leq-2.5 S D\end{array}$ & $\begin{array}{l}25 \\
3 \\
2\end{array}$ & $\begin{array}{l}17 \\
1 \\
2\end{array}$ \\
\hline $\begin{array}{l}\text { Left Forearm } \\
\geq-1 \text { SD } \\
-1 \text { to }-2.5 S D \\
\leq-2.5 S D\end{array}$ & $\begin{array}{l}25 \\
3 \\
2\end{array}$ & $\begin{array}{l}17 \\
1 \\
2\end{array}$ \\
\hline P value & 0.214 & 0.336 \\
\hline
\end{tabular}

\begin{tabular}{|c|c|c|c|c|}
\hline \multirow{2}{*}{$\begin{array}{l}\text { Bone Density } \\
\text { T- score }\end{array}$} & \multicolumn{4}{|c|}{ Duration of antipsychotic intake } \\
\hline & 2-4 yrs & 4-6 yrs & 6-8 yrs & 8-10 yrs \\
\hline$\geq-1 S D$ & 0 & 0 & 0 & 0 \\
\hline-1 to $-2.5 \mathrm{SD}$ & 6 & 8 & 2 & 5 \\
\hline$\leq-2.5 \mathrm{SD}$ & 0 & 0 & 5 & 4 \\
\hline
\end{tabular}

may lead to prolonged stressful condition by creating a false imagined danger [22,23]. However, this finding exclude hypercortisolemia as a hypothesized etiology for poor bone mineralization density.

Hyperprolactinemia as an endocrinological dysfunction comes among main etiologies to secondary osteoporosis, due to its direct effect on bone mineralization on one side and decreasing sex hormones on the other side. Many authors, as in our study, highlighted such association between elevated prolactin level and poor bone density and subsequent pathological fractures $[24,25]$.

\section{Conclusion}

Pathologically decreased bone mineral density is a prevalent side effect among schizophrenic patients with long term use of antipsychotics. A health problem that's often overlooked though it's important negative impact on health state

\section{Limitation}

Our study is limited by small sample size and the cross sectional rather than cohort design assessing effect of antipsychotics on the same patient over time with reference to baseline levels. Since osteoporosis is a complex pathology with multiple contributing risk factors, other parameters may confer confusion bias were not included in comparisons due to small groups however future studies may also involve body mass index, estradiol and testosterone levels. Though our study showed higher prevalence of osteoporosis with longer duration of antipsychotic use but it didn't assess correlation with total illness duration rather than therapy duration. 


\section{References}

1. Wright NC, Looker AC, Saag KG, et al. The recent prevalence of osteoporosis and low bone mass in the United States based on bone mineral density at the femoral neck or lumbar spine. J. Bone Mine. Res 29(11), 25202526 (2014).

2. Malgo F, Appelman-Dijkstra N, Termaat F, et al. Secondary causes for osteoporosis significantly contribute to fracture risk in patients with osteopenia and a recent fracture. Bone. Abs 3(1), 271 (2014)

3. Dutta D, Dharmshaktu P, Aggarwal A, et al. Severity and pattern of bone mineral loss in endocrine causes of osteoporosis as compared to age-related bone mineral loss. J. Postg. Med 62(3), 162 (2016).

4. De Hert M, Detraux J, Stubbs B. Relationship between antipsychotic medication, serum prolactin levels and osteoporosis/ osteoporotic fractures in patients with schizophrenia: a critical literature review. Exp. Opi. Drug. Safety 15(6), 809-823 (2016).

5. Wang M, Hou R, Jian J, et al. Effects of antipsychotics on bone mineral density and prolactin levels in patients with schizophrenia: a 12-month prospective study. Hum. Psychopharmacol 29(2), 183189 (2014).

6. D'Sylva C, Khan T, Van Uum S, et al. Osteoporotic fractures in patients with untreated hyperprolactinemia vs. those taking dopamine agonists: A systematic review and meta-analysis. Neuroendocrinol. Lett 36(8), 745-749 (2015).

7. Meltzer HY. Update on typical and atypical antipsychotic drugs. Annual review of medicine. 64(1), 393-406 (2013).

8. Jian-An Su, Bi-Hua Cheng, Yin-Cheng Huang, et al. Bipolar disorder and the risk of fracture: A nationwide population-based cohort study. J. Affect. Disor 218(1), 246-252 (2017).
9. Motyl KJ, Beauchemin M, Barlow D, et al. A novel role for dopamine signaling in the pathogenesis of bone loss from the atypical antipsychotic drug risperidone in female mice. Bone 103(1), 168-176 (2017).

10. Pawlak D, Domaniewski T, Znorko B, et al. The impact of peripheral serotonin on leptin-brain serotonin axis, bone metabolism and strength in growing rats with experimental chronic kidney disease. Bone 105(1), 1-10 (2017).

11. Motyl KJ, DeMambro VE, Barlow D, et al. Propranolol attenuates risperidone-induced bone loss in female mice. Endocrinology 156(7), 2374-2383 (2015).

12. Yang $H, X u Y, Z$ hu $M$, et al. Inhibition of titanium-particle-induced inflammatory osteolysis after local administration of dopamine and suppression of osteoclastogenesis via D2-like receptor signaling pathway. Biomaterials $80(1), 1-10$ (2016).

13. Tanaka K, Hirai T, Ishibashi Y, et al. Modulation of osteoblast differentiation and bone mass by $5-\mathrm{HT} 2 \mathrm{~A}$ receptor signaling in mice. Eur. J. Pharmacol 762(1), 150-157 (2015).

14. Speaks A. DSM-5 diagnostic criteria (2013).

15. Von Lode P, Rosenberg J, Pettersson K, et al. A europium chelate for quantitative pointof-care immunoassays using direct surface measurement. Analyt. Chem 75(13), 31933201(2003).

16. Espinosa De Ycaza AE, Rizza RA, Nair KS, et al. Effect of dehydroepiandrosterone and testosterone supplementation on systemic lipolysis. J. Clin. Endocrinol. Metab 101(4), 1719-1728 (2016).

17. Van der Sluis IM, De Ridder MA, Boot AM, et al. Reference data for bone density and body composition measured with dual energy $x$ ray absorptiometry in white children and young adults. Arch. Dis. Child
87(4), 341-347 (2002).

18. Jones E. Antipsychotics and osteoporosis: current awareness and practice in primary care. Br. J. Gen. Pract 64(628), 562-563 (2014).

19.

20. Stubbs B, De Hert M, Sepehry AA, et al. A meta-analysis of prevalence estimates and moderators of low bone mass in people with schizophrenia. Acta. Psychiatr. Scand 130(6), 470-486 (2014).

21. Wu H, Deng L, Zhao L, et al. Osteoporosis associated with antipsychotic treatment in schizophrenia. Int. J. Endocrinol 2013(1), 167138 (2013).

22. Fraser LA, Liu K, Naylor KL, et al. Falls and fractures with atypical antipsychotic medication use: a population-based cohort study. JAMA. Int. Med 175(3), 450-452 (2015).

23. Handley R, Mondelli V, Zelaya F, et al. Effects of antipsychotics on cortisol, interleukin-6 and hippocampal perfusion in healthy volunteers. Schizophr. Res 174(1), 99-105 (2016).

24. Girshkin L, Matheson SL, Shepherd AM, et al. Morning cortisol levels in schizophrenia and bipolar disorder: a meta-analysis. Psychoneuroendocrinology 49(1), 187-206 (2014).

25. Takahashi $T$, Uchida $H$, John $M$, et al. The impact of prolactin-raising antipsychotics on bone mineral density in patients with schizophrenia: findings from a longitudinal observational cohort. Schizophr. Res 147(2), 383-386 (2013).

26. Bulut SD, Bulut S, Tüzer V, et al. The Effects of Prolactin-Raising and Prolactin-Sparing Antipsychotics on Prolactin Levels and Bone Mineral Density in Schizophrenic Patients. Neuro. Psychiatry. Arch 51(3), 205 (2014) 